\title{
Juan Eduardo Bustos-Obregón (1937-2014)
}

\author{
Juan Eduardo Bustos-Obregón (1937-2014)
}

Joaquín Rivas*; Jorge Bustos** \& Mariana Rojas***

\begin{abstract}
RIVAS, J.; BUSTOS, J. \& ROJAS, M. Juan Eduardo Bustos-Obregón (1937-2014). Int. J. Morphol., 32(4):1509-1516, 2014.
RESUMEN: El siguiente es un tributo a la vida del Dr. Eduardo Bustos Obregón, de quienes, sin ser sus hijos, construimos junto a él una familia. Las vivencias más antiguas que aquí compartimos fueron extraídas de relatos de su madre y de las historias que él nos contaba, pero la mayoría son cosas y experiencias que vivimos cada uno de nosotros durante tantos años y que intentamos describir según el método científico que él utilizó siempre.
\end{abstract}

PALABRAS CLAVE: Bustos-Obregón; Morfología; Andrología; Biología Reproductiva.

\section{INTRODUCCIÓN}

Juan Eduardo Bustos Obregón nació el 13 de Octubre de 1937, en Santiago de Chile. Fue el mayor de tres hermanos (Eduardo, Nelson y Julián). Vino al mundo apenas tras 6 meses y medio de gestación y pesó 650 gr. En ese tiempo no existían los avances que existen hoy, en cuanto a tratamientos para facilitar la maduración pulmonar del recién nacido prematuro. Pese a estar desahuciado, logró sobrevivir, a pesar de quedar con algunos problemas respiratorios y es así como podemos verlo en la Fig. 1, con dos años cumplidos. (Hortensia Obregón comunicación personal).

Estudió en el Instituto Nacional. Allí siempre se destacó por ser un excelente alumno y por su "sobresaliente personalidad", según se indica en el diploma de honor. En esa época escolar, solía encargarse de poner la música en el recreo. Su obra favorita era el Concierto para Piano de Grieg, y al hacerla sonar siempre recibía la desaprobación y pifias de todos sus compañeros de colegio.

Ingresó a la Universidad de Chile para estudiar Medicina. En esa facultad inició su actividad académica como ayudante alumno de la cátedra de Biología Celular y Genética en el Instituto de Biología "Juan Noé", mientras cursaba segundo año de Medicina, carrera que terminó en el año 1963 con el título de médico cirujano.

Sus estudios de postgrado los realizó en la Universidad de Tulane (USA) y la Universidad Mc Gill (Montreal, Canadá), mediante una beca de la Fundación Rockefeller, y en el Instituto de Anatomía de la Clínica Universitaria de Eppendorf (UKE, en Hamburgo, Alemania), gracias a una beca de la Fundación A. Von Humboldt, que le permitió también trabajar en los laboratorios del Instituto Nacional de Investigación Agronómica (INRA), en las ciudades de Nouzily y Jouy-en-Josas, Francia (comunicación personal).

* DeNA, Chile.

** Asociación Chilena de Seguridad, Puerto Mott, Chile.

*** Programa de Anatomía y Biología del Desarrollo, Facultad de Medicina, Universidad de Chile, Chile.

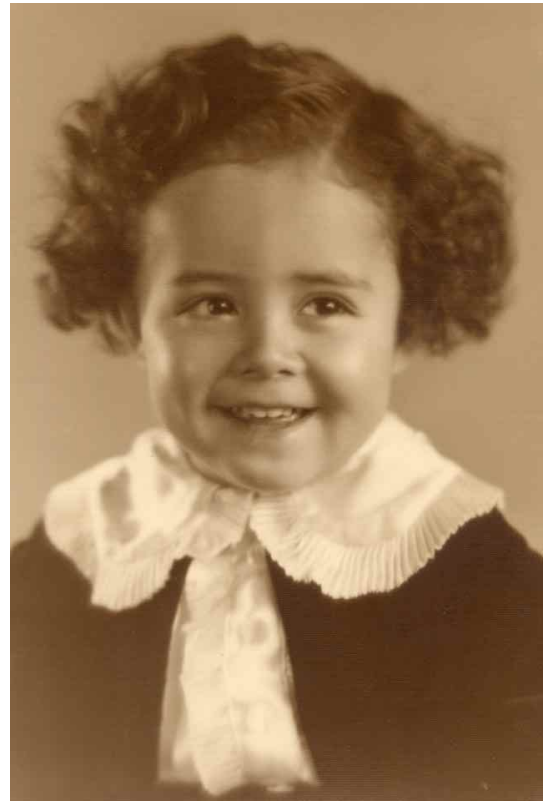

Fig. 1. Juan Eduardo Bustos-Obregón a los dos años de edad.

Durante su carrera académica, se dedicó a la docencia e investigación en Biología de la Reproducción, con énfasis en la Andrología (Fig 2). Fue autor de más de 200 publicaciones, pro- 
fesor tutor de 60 tesistas de pregrado y de 30 tesistas de postgrado, y recibió a 16 becados extranjeros para estadías de especialización.

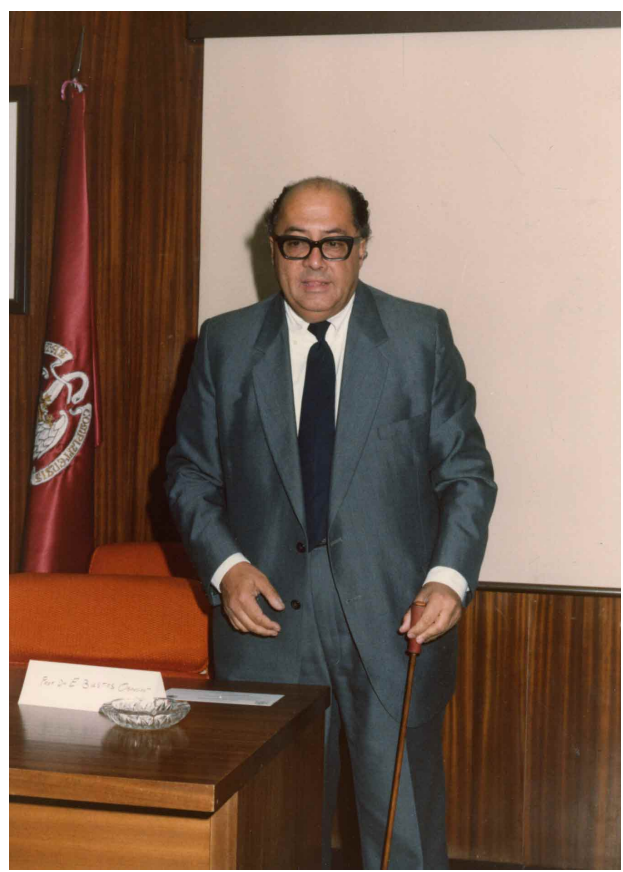

Fig. 2. Presentando una Conferencia como Profesor Titular de la Universidad de Chile.

Eduardo Bustos-Obregón era muy inteligente, exigente, detallista y riguroso. Parecía vivir a un ritmo distinto al de los demás. Buscaba aquellas soluciones que unían los cabos sueltos que el estudio en curso había presentado y en el caso de las tesis, guiaba a sus alumnos para que fueran capaces de realizar este proceso por sí mismos (Fig, 3.). En ocasiones, él costeaba las investigaciones y las inscripciones a Congresos y Cursos, y decía: "Financiado con los Fondos de la Fundación Bustos-Obregón Je Je".

Fueron inolvidables los múltiples "safaris" que solíamos realizar durante las vacaciones de verano y de invierno, quizás muchos colegas y tesistas habrán conocido sus habilidades al volante al viajar a través de los "caminos pintorescos" (donde mientras peores fueran las condiciones del camino, y más desconocidos los pueblos que podía hallar, mayor era el atractivo). En estos safaris se escuchaba música clásica, o se cantaba junto con el los boleros, música tropical, can- ciones de María Bethania, o "Paquita la del barrio". También le gustaba compartir con sus tesistas y colegas un asado en "La Chalona", su casa en la playa de Algarrobo, donde disfrutaba contando las anécdotas de sus diversos viajes por el mundo.

En sus periplos, siempre buscaba la opción de poder ver espectáculos musicales, museos y, en caso de haber, ruinas de misiones jesuitas. Le gustaba leer sobre la cultura griega, la romana y la egipcia, pero también sobre la cultura y la política latinoamericana (lo cual puede estar relacionado con su otra pasión, que era el mejoramiento de la educación e nuestro país, en lo que trabajó durante gran parte de su vida incluso fue Vicepresidente de la Comisión Nacional de Acreditación de Postgrado (CNAP) y de otras entidades de Educación.

Tuvo una vida familiar, en compañía de su madre Hortensia, de María Isabel, y de nosotros. Siempre se preocupó de nuestra salud y estado de ánimo, de que no nos faltara nada, Incluso tuvo que traernos de vuelta desde España a Joaquín y a mí (Mariana), pocos días después que naciera Joaquín. Igualmente tuvo que salir a buscar a Jorge "con el alma en un hilo" cuando se lanzó en paracaídas y sufrió un accidente. ¡Cómo olvidar aquella vez que Mariana se perdió en Londres y el llamó por teléfono a todos sus colegas y amigos hasta que logró encontrarla!. Sin embargo, si hay algo que lo caracterizó como un sello de crianza, fue el intentar prepararnos para tener un buen desempeño en un nivel de competitividad de máxima exigencia a nivel internacional, y el que fuéramos capaces de solucionar los problemas laborales (Fig 4). Últimamente se había centrado en enseñar a Catalina, su nieta de dos años el arte de utilizar la cuchara para tomar la sopa correctamente.

En particular destacaba por su carácter de maestro y de padre. Estas características las desarrolló desde muy joven haciéndose cargo como

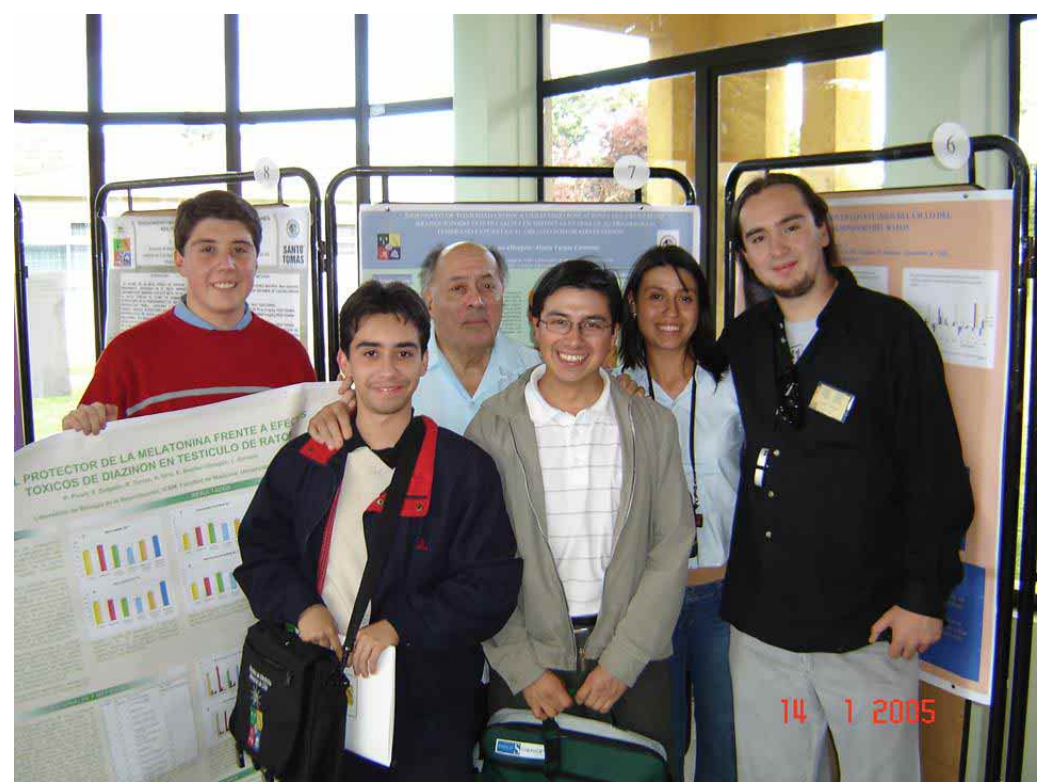

Fig. 3. Compartiendo con sus tesistas y ayudantes en el congreso de SAGACH en la Universidad de La Frontera en Temuco. De derecha a izquierda. Eduardo Valdivia, Raul Torres, Luis Sarabia, Paula Manzor y Alvaro Vargas. 
profesor de la educación y preparación de su hermano menor Julián, que lo impulso a ser el destacado profesional que es hoy, luego con Mariana, con Jorge su sobrino y finalmente con Joaquín. De esta forma fue un gran padre en todos sus ámbitos, sentándose a estudiar con su hermano, guiando a Mariana en su carrera y crecimiento, acompañando a su sobrino a la fría y polvorienta galería del festival de la canción de viña del mar, preocupándose del como un padre luego de la muerte prematura de su hermano Nelson. Transmitir el amor por la música, desde los boleros y el bossa nova hasta la ópera y los conciertos, el amor por la ciencia y el pensar siempre más allá. Podía pasar de ser el más serio y riguroso maestro a ser el alma de la fiesta con su música e instrumentos.

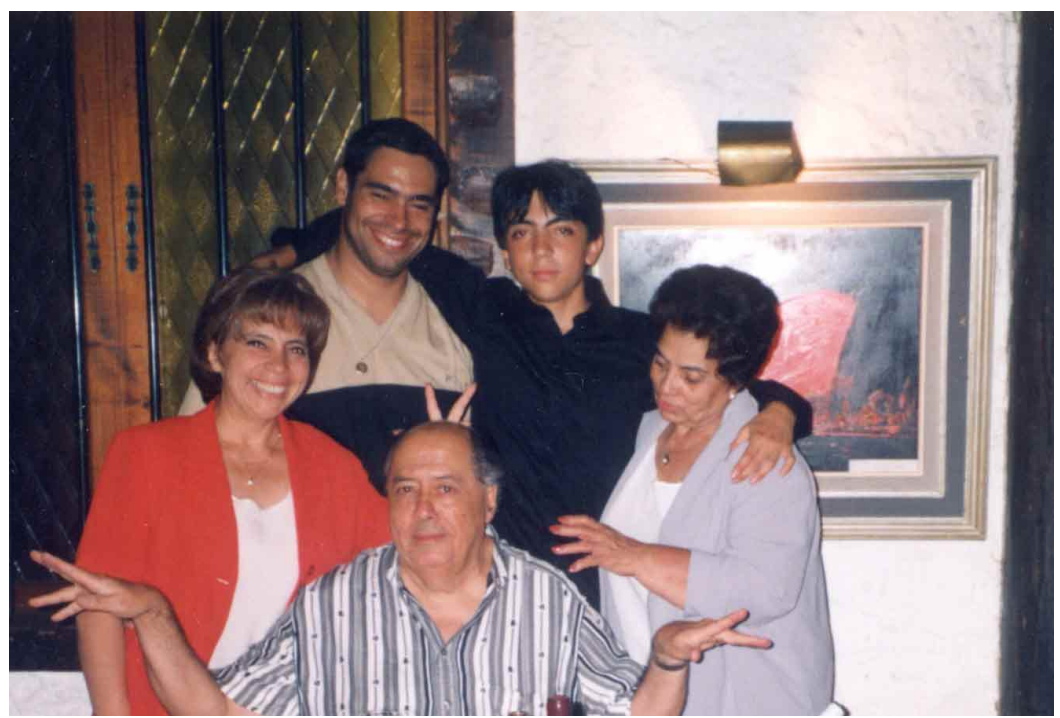

Fig. 4. Celebrando los 15 años de Joaquín. JEBO, Mariana Rojas, Jorge Bustos, Joaquín Rivas, María Isabel Rauco.

\section{MÉTODO DE VIDA}

Durante su trayectoria, Eduardo Bustos-Obregón utilizó directrices que fueron construyendo su identidad como académico, y las cuales revisaremos en orden cronológico.

Primero se inspiró en una frase del discurso de Andrés Bello con motivo de la instalación de la Universidad de Chile que dice: "Todas las sendas en que se propone dirigir las investigaciones de sus miembros, y el estudio de sus alumnos, convergen a un centro: la patria".

En la Universidad de Tulane, una de las prácticas que adoptó fue el esquema de Bioética y Honour System. Allí, los alumnos rendían sus pruebas sin vigilancia alguna de los docentes, incentivando la autoevaluación necesariamente crítica en el trabajo académico.

Ya en Montreal, incluiría entre sus hábitos la recomendación del Prof. Dr. C.P. Leblond, Chairman de la Universidad Mc Gill, quien aconsejaba anotar las ideas interesantes relacionadas con investigación en una libreta (notebook), porque de ese modo nunca cesa la creatividad.
Siempre recalcó la necesidad de conocer al menos dos idiomas de importancia a nivel mundial. Èl hablaba cuatro. Solía recurrir a una anécdota en su cena de despedida de Canadá, donde una tesista estadounidense le pide que escoja una entrada del menú por ella, ya que estaba en francés y ella no comprendía dicho idioma. Mientras esperaban el plato principal, un Omelette de l'Amour, ella consulta a su tutor, el Prof. Dr. Y. Clermont, que había comido como entrada, a lo que él le responde: “¿Tanto tiempo trabajando con ese material y aún no lo reconoces? El plato estaba preparado con criadillas (Fig 5).

De su experiencia en Alemania, nos ha comentado que, a la entrada de la sala de microscopía de la UKE, en Hamburgo, había una frase de Virchow, como mensaje a los alumnos que comienzan su carrera en la Morfología, pero aplicable a cualquier actividad humana. "Mirar no es Observar", ya que observar implica un nivel de análisis y juicio sobre el objeto de estudio, que va más allá de una superflua mirada.

Finalmente, siempre señalaba las últimas palabras de Goethe ("Luz, más luz"), refiriéndose a la necesidad de analizar los problemas mediante una visión integral y colaborativa, incluyendo todas las aristas que pueden afectar a la comprensión de un problema, en vez de realizar investigación aislados por secciones, y sin una debida retroalimentación entre los sistemas relacionados. Sobre esto también nos conversó, con mucha emoción horas antes de morir.

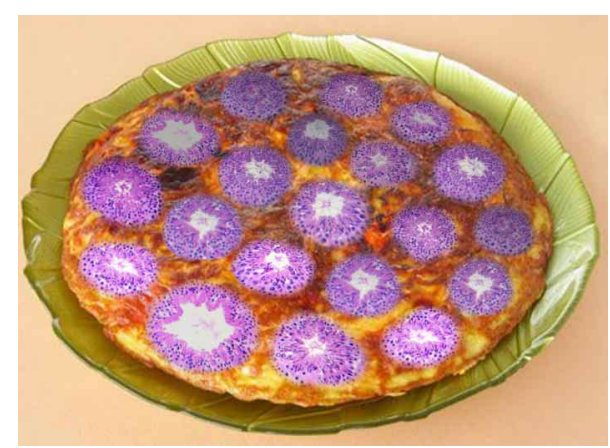

Fig. 5. Omelette de l'amour. 


\section{Logros del Prof. Doctor Bustos-Obregón}

Con las directrices señaladas logró realizar muchas publicaciones y trabajar con académicos de las distintas regiones del país, de Latinoamérica y Europa.

1) Su primeras publicaciones correspondieron al estudio del testículo tanto de la especie humana, como de animales de laboratorio (Clermont \& Bustos, 1966, Bustos \& Holstein, 1973; Bustos \& Esponda, 1974; Bustos et al, 1975) y de interés veterinario (Bustos \& Courot, 1974).

Después analizó el ciclo reproductivo de animales estacionales autóctonos, tanto de Chile como de los países de origen de sus tesistas. (Potocnjak \& Bustos, 1977., Contreras \& Bustos Obregón, 1980., Persona \& Bustos Obregón, 1983., Olivares et al, 1983; Breucker, et al., 1989, Bustos et al, 1997, Paolicchi et al., 1999. Rodriguez et al., 1999., también en modelos de laboratorio (Brown et al., 1988, Contreras \& Bustos-Obregón, 1980, Vigil,\& Bustos-Obregón,1985).

Una de las líneas en las cuales trabajó con gran entusiasmo fue en la chalona espermatogonial (Bustos \& Thumann,1979., Bustos-Obregón 1984; 1985). Incluso su casa de la playa se llama Chalona y en la entrada encontrará un corte histológico de un túbulo seminífero hecho en mosaico por un artista de España.

Un aporte importante fue dar a conocer los factores ambientales que afectan la función reproductiva del testícu- lo tales como la hipoxia, la edad, y contaminantes ambientales (pesticidas y metales pesados: plomo, boro). Como también la evaluación del rol protector de distintas sustancias, tanto químicas como naturales sobre la función reproductiva de los organismos expuestos a los contaminantes descritos anteriormente. (Contreras et al, 1996., Bustos-Obregón et al, 1998., Bustos-Obregón \& Hartley, 2008., Bustos-Obregón et al., 2008, 2010, 2013., Vargas et al, 2011, Bustos Obregón \& Olivares 2012., Valenzuela et al., 2014).

Paralelamente, a las actividades de investigación fue presidente de la Sociedad de Biología de Chile (1979-1980) y en el año 1987 fundó la Sociedad Chilena de Reproducción y Desarrollo. La SCHRD fue tramitada legalmente ante el Ministerio de Justicia, bajo el decreto no 1322 del 15 de enero de 1988. Su propósito fue promover la actividad científica fuera de Santiago a través de reuniones regionales. Propiciar trabajos de investigación relevantes al Desarrollo y Producción. También se incentivó la participación de socios-alumnos previa a su titulación presentando como trabajo de incorporación su tesis de pre o postgrado. Esta tarea la realizó junto a los Drs. Claudio Barros y Jorge Arrau (comunicación personal).

Además fue miembro del Comité Científico del Programa Latinoameri-cano de Investigación en Reproducción Humana (PLAMIRH). Miembro de la Academia de Ciencias de America Latina (ACAL) (1994). Miembro Vitalicio de la Sociedad Chilena de Endocrinología y Metabolismo. Presidente de la Sociedad de Andrología y Gametología de Chile (Fig 6) y Profesor Honorifico de la Facultad de

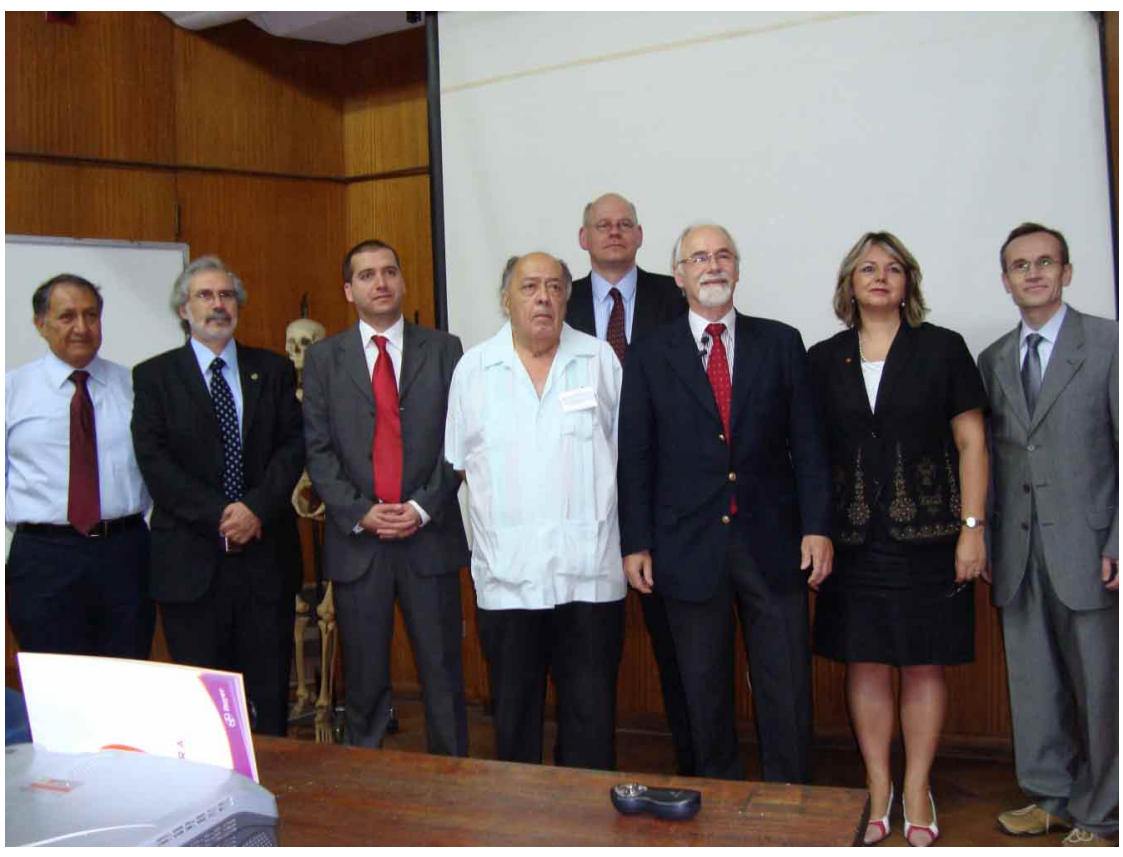

Fig. 6. Congreso de Andrología realizado en la Fac de Medicina. Universidad de Chile. Fernando Vásquez (Colombia), Raúl Sánchez (Chile), Marcelo Marconi (Chile) JEBO (Chile), Wolf-BernardSchill (Alemania) Rosemarie Heyn (Chile). Jorma Toppari, (Finlandia), segunda fila: Andreas Mainhardt (Alemania). 


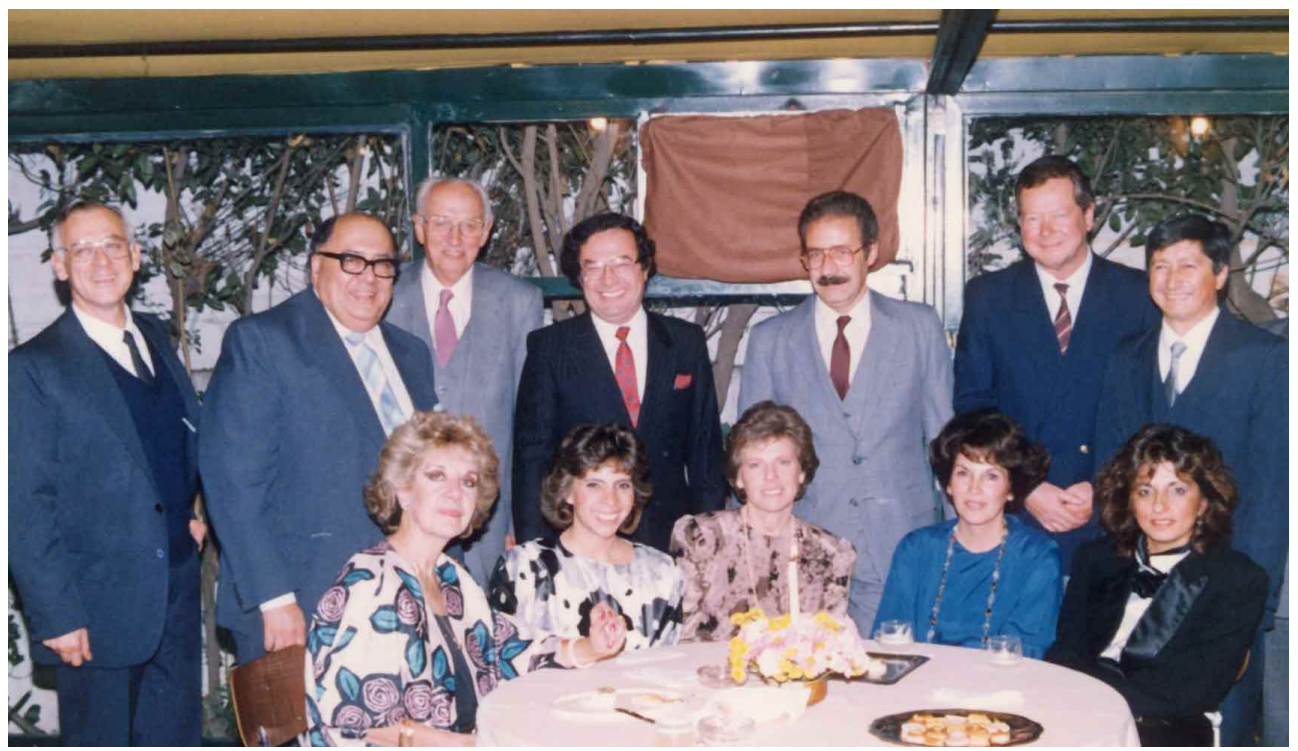

Fig. 7. Maestros, amigos y colegas. Jorge Arrau, Eduardo Bustos, Gustavo Höecker, Claudio Barros, Rafael Blanco, Francisco Rothhamer, Hernán Palominos, Alicia Ramos, Mariana Rojas, María Angélica Montenegro, Mónica Suarez y Mónica Acuña.

Medicina, Universidad de La Frontera, Temuco (Chile) y también participó en la Sociedad Chilena de Anatomía.

Fue Director Académico de la Facultad de Medicina, Universidad de Chile, Coordinador Técnico Nacional PNUD/UNESCO, Editor Asociado de International Journal of Andrology, Editor Asociado de la Revista Andrología, Miembro del Comité Editor de Revista Iberoaméricana de Fertilidad y Reproducción Humana, Barcelona, España. Miembro del Comité Editor de Molecular Andrology (USA). Co-Editor de International Journal of Andrology (England). En la Universidad de Chile fué Director de Pregrado de la Vicerrectoría Académica y Estudiantil, Vicepresidente de la Comisión Nacional de Acreditación de Postgrado (CONAP).

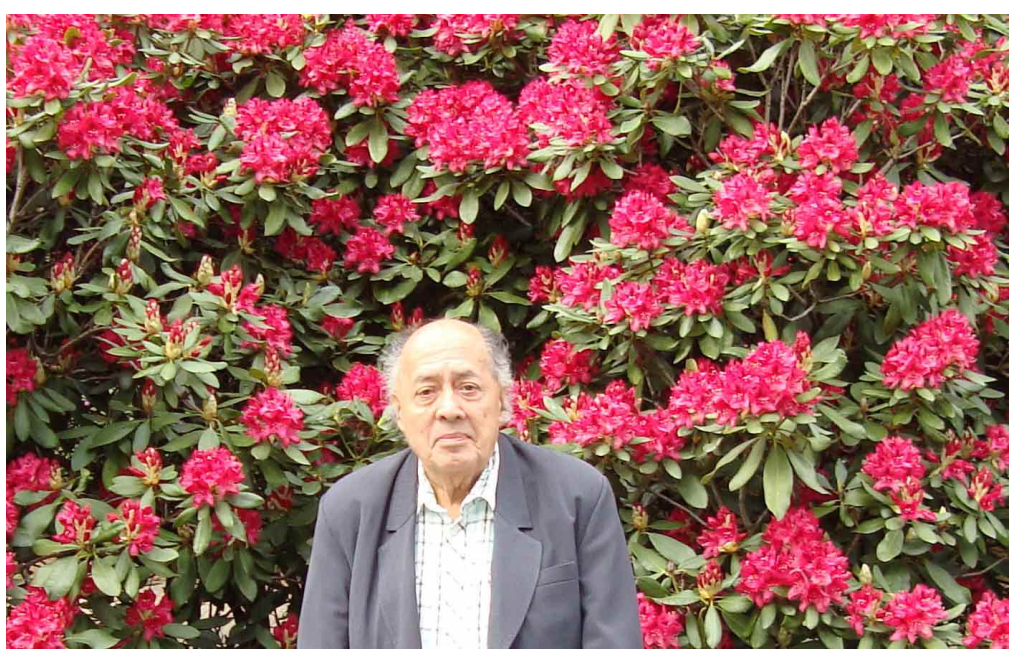

Durante su vida ejerció los más altos cargos en la Universidad de Chile y recibió muchos premios y homenajes, de distintas instituciones nacionales e internacionales, Sin embargo, el nunca olvidó a sus maestros de Chile (Gustavo Hoecker y Alicia Ramos) y siempre se sintió agradecido con sus amigos de antaño, entre ellos, Claudio Barros, Jorge Arrau, María Angélica Montenegro (Fig.7), Javier Regadera y Pedro Esponda de España, Jacques Fléchon de Francia, PatricK Horne de Canadá y de muchos de sus colegas andrólogos y biólogos que nosotros no conocemos y también de todos y cada uno de sus tesistas, Entre todos los premios, hubo uno que a nosotros nos llenó de orgullo y alegría. Fue el Auditorio Eduardo Bustos-Obregón en la Universidad de Antofagasta, inaugurado por su decano, Marco Cikutovic, hace muchos años atrás, Además, pudimos ver que en el trato cotidiano era recibido en todos los lugares del mundo como "maestro".

Aun cuando el profesor Eduardo Bustos Obregón trabajó hasta el último día de su vida, preparando presentaciones a Congresos $\mathrm{y}$ publicaciones y dirigiendo tesis, $\mathrm{y}$ aun cuando su producción científica fue muy importante y extensa decía que quedaban temas pendientes de la andrología, como sentar las bases del derecho reproductivo del hombre, y

Fig. 8. Prof. Dr. Juan Eduardo Bustos-Obregón a los 75 años de edad. 
permitir la comprensión de los mecanismos que influyen en su capacidad reproductiva de la misma manera como esto ocurre en la mujer. El dijo lo siguiente en una conferencia que presentó en Brasil: "Felicito a los ginecólogos. Es importante que los derechos reproductivos de la mujer estén protegidos, pero esto también marca un desafío para la Andrología, es nuestro deber sentar las bases de los derechos reproductivos masculinos".

Nos sentimos muy honrados y felices de haber compartido prácticamente todas nuestras vidas con él, viviendo en su casa, admirando el ejemplo de trabajar con energía y entusiasmo, siempre al máximo, aun cuando la salud no acompañe o se haya perdido la vista, o que no se pueda caminar, que el corazón funcione solo al $30 \%$ o que ya no se pueda respirar. Aun ahora que nos dejó, estamos seguros que proliferarán nuevos trabajos, quizás algunos liderados por Ricardo Hartley, Roberto Catriao y muchos otros de sus colegas que trabajaban con él y lo estimaban.

Antes de terminar este reconocimiento, incluiremos los testimonios de cuatro colegas que a nosotros nos causaron mucha emoción. Agradecemos además a las personas que llegaron de todo Chile a decirle adiós y a todos quienes enviaron sus correos electrónicos desde Argentina, Alemania, Brasil, Colombia, España, Francia, Nicaragua o desde otras ciudades de Chile para que nosotros no tuviésemos tanta pena y dolor. Un especial cariño para ellos.

El Dr Fernando Vásquez (Colombia) lo recuerda así: "Cuando en 1988 llegué a Santiago, fui recibido por los brazos afectuosos de quien a partir de ese día sería un amigo, un familiar, un maestro, un guía, un formador de mi carrera investigativa, el tío Bustos de mis hijos, el compañero de viaje por el mundo, el multiplicador de mis amistades, el amigo fraternal de mi esposa Patricia, el mejor cantor de música colombiana y boleros, el hombre de las anécdotas más curiosas que contadas por él relajaban el espíritu".

El Dr. Mariano del Sol (Chile) nos entrega el siguiente relato: "De Eduardo, guardaré los recuerdos imborrables de un hombre sincero, amable y admirable, quien en vida ayudó a todos sin esperar nada. Fue un ferviente defensor de la Morfología apoyándonos incansablemente cuando iniciamos primero el Magíster y luego el Doctorado en Ciencias Morfológicas en la Universidad de La Frontera. Se ha ido un amigo, un compañero de ruta universitaria, un colega que colaboró fuertemente con la Revista Chilena de Anatomía. Él era un maestro, pero paradojalmente él me llamaba así. Conversar con Eduardo era entretenido y divertido. Sus anécdotas de la inmensa experiencia acumulada las compartía con sus amigos, colegas y alumnos. Echaremos de menos esos buenos momentos de sana convivencia".
Dr. Octavio Guevara Villavicencio (Rector de la Universidad Nacional Autónoma de Nicaragua), lo describe de esta forma. "El Dr. Bustos-Obregón, con su pérdida, deja un vació en la Sociedad Médica. Se destacó por ser el pionero de los estudios en infertilidad masculina, en la Facultad de Ciencias Médicas de la UNAN, León en el año 2001. Nos deja un legado como hombre de ciencia y de conciencia, su incondicional apoyo con nuestra Universidad, nos permitirá tenerlo siempre presente como símbolo de amistad, solidaridad y unidad, ejemplo de gran personalidad humana, espiritual y científica".

Dra. Rosa Devés, Vicerrectora de la Universidad de Chile. Es un honor manifestar en representación de la Universidad de Chile nuestro respeto y agradecimiento a la persona, la vida y el trabajo académico del Doctor Eduardo Bustos Obregón, siendo la Universidad parte esencial de su ser y él mismo parte esencial del ser de la Universidad.

Antes que nada Maestro. Maestro de muchos y maestro siempre. Su energía desbordante le permitió realizar innumerables tareas de dirección y liderazgo académico sin dejar nunca de ser esencialmente un profesor preocupado del desarrollo y la ampliación de las capacidades de los demás.

Al mismo tiempo desarrolló con excelencia una identidad disciplinar, era profesor y era biólogo celular experto en biología de la reproducción. Era ... no sólo se dedicaba a... No es tan obvio como se forja la identidad de un académico, no es simplemente la suma de una formación especializada y de la investigación en un tema específico. Tiene también mucho que ver con cómo se hace cargo de desarrollar, pero también de resguardar y cuidar la integridad de una disciplina. Es algo que se construye en años, que lo aprendemos de las comunidades a las cuales nos vamos integrando en forma a veces inconsciente. Es importante entenderlo para apoyarlo desde nuestros planes de formación. La vida del Dr. Eduardo Bustos nos muestra un camino.

Finalmente, una mención a la claridad con que siempre entendió la responsabilidad que la Universidad de Chile tiene - por historia y misión - de colaborar con el desarrollo del sistema universitario fuera de sus límites formales. Su incansable preocupación por el desarrollo del sistema universitario en distintas regiones de Chile, fue también ejemplar. Unas semanas atrás participé en una actividad en la Universidad de Antofagasta en el auditorio Eduardo Bustos Obregón y el resultado de su acción generosa se hacía evidente en cada encuentro, él había sido central para el desarrollo de líneas de investigación, había abierto múltiples oportunidades de formación para personas de distintas edades, hasta matrimonios y familias debían su existencia al espacio formativo que él había creado. 
Gracias Profesor, por su inteligencia, su carácter, su pasión, respeto y agradecimiento de la Universidad de Chile para usted y profundo afecto para su familia

Quisiéramos terminar este tributo con las palabras que solía utilizar Eduardo Bustos-Obregón al terminar sus escritos de extensión. (Fig. 8) "Considero que lo auténtico no es censurable, que lo académico no es necesariamente solemne o acartonado, y que lo vivido se expresa mejor en forma espontánea”. ¡iMuchas Gracias!!.

RIVAS, J.; BUSTOS, J. \& ROJAS, M. Juan Eduardo Bustos-Obregón (1937-2014). Int. J. Morphol., 32(4):1509-1516, 2014.

SUMMARY: The following is a tribute to the life of Dr. Eduardo Bustos Obregón, we build a family with him The earliest experiences that here we share were drawn from accounts of his mother and the stories he told us the same, but most are things and experiences that we live each of us for so many years and we try to describe as the scientific method that always used.

KEY WORDS: Bustos-Obrtegón; Morphology; Andrology; Reprodctive biology.

\section{REFERENCIAS BIBLIOGRAFICAS}

Breucker, H.; Schafer, Elke \& Bustos-Obregón, E. "Spermatogenesis of Lophonetta specularioides (Anatidae, Aves) in the high plateau of the southern andes. Alight and electron microscopic study". Micr. Electr. Biol. Cel. 13(2):167-82. 1989.

Bustos, E. \& Holstein, A. F. On structural patterns of the lamina propria of human seminife-rous tubules. Z. Zellf. Mikrosk. Ant., 141:413-25, 1973.

Bustos, E. \& Courot, M. Ultrastructure of the lamina propria of the ovine seminiferous tubule. Development and some endocrine considerations. Cell Tissue Res., 150:481-92, 1974.

Bustos, E. \& Esponda, P. Ultrastructure of the nucleus of human Sertoli cells in normal and pathological testis. Cell Tissue Res., 152:467-74, 1974.

Bustos, E.; Courot, M. \& Flechon, J. E., Hochereau-de-Reviers, M.T. \& Holstein, A.F. Morphological appraisal of gametogenesis. Spermatogenic process in mammals with particular reference to man. A Review. Andrologie, 7: 141, 1975.

Bustos, E. Ultrastructure and function of the lamina propria of mammalian seminiferous tubules. Andrologie, $8: 179,1976$.

Bustos, E. \& Thumann, A. La chalona espermatogo-nial. Revisión crítica de la proliferación espermatogonial. Rev. Latinoam. Micr. Electr. y Biol. Cel., 6:303, 1979

Bustos-Obregón, E. Tissue chalones, with special reference to the spermatogonial chalones. In: Regulation of target cell responsiveness. Ed. Kenneth W. Mc Kerns, Plenum Publishing Corp. New York, USA Vol. 2:403-32, 1984.

Bustos-Obregón, E. Spermatogonial proliferation: Role of the chalones. Andrology: Infertility and Sterility. Academic Press Inc., New York, USA, 1985.
Bustos-Obregón, E.; Valenzuela-Estrada, M. \& Rojas, M. "Agropesticides and testicular damage" In: Male Reproduction. A multidisciplinary overview. Ed: MartinezGarcía, F., Regadera, J. Churchill communications Europe España, pp 257-264 . 1998.

Bustos-Obregón, E \& Hartley, B. Ecotoxicology and testicular damage (Environmental chemical pollution). A Review. Int. J. Morphol., 26(4):833-40, 2008.

Bustos-Obregón, E.; Hartley, R.; \& Catriao R. Histopathological effects of boron on mouse liver. Int. J. Morphol.26 (1):15564, 2008.

Bustos-Obregón, E.; Castro-Sánchez, R.; Ramos-González, B. \& Torres-Díaz, L. Rat spermatogenesis damage in intermittent hypobaric hypoxia and the protective role of melatonin. II: testicular parameters. Int. J. Morphol., 28(2):37-547, 2010.

Bustos-Obregón, E. \& Olivares, C. Boron as testicular toxicant in mice (Mus domesticus). Int. J. Morphol., 30(3):1106-1114, 2012.

Bustos-Obregón, E.; Poblete, D.; Catriao, R.; del Sol, M. \& Fernandez, F. H. Melatonin protective role in mouse cauda epipidymal spermatozoa damage induced by sodium arsenite. Int. J. Morphol., 31(4):1251-56, 2013.

Clermont, Y \& Bustos, E. Identification of five classes if type A spermatogonia in rat seminife-rous tubules mounted "in toto". Anat. Rec., 154:332, 1966.

Contreras, L. \& Bustos-Obregón, E. Anatomy of reproductive tract in Octodon degus (Molina) : a nonscrotal rodent. Arch. Androl., $4: 115-24,1980$.

Olivares, A.: Estica, O.; Leiva, J.; Troncoso, C. \& Bustos-Obregón, 
E. Reproductive cycle in Phyllodactylus gerrhopygus (Weigmann), 1835. Micr. Electr. \& Biol. Cel., 7(1):39-47, 1983.

Persona, L. \& Bustos-Obregón, E. Seminiferous epithelium cycle in the armadillo. Arch. Andrology 10:113-8, 1983.

Paolicchi, F.; Urquieta, B.; Del Valle, L.; Bustos-Obregón, E. "Biological activity of the seminal plasma of alpacas : stimulus for the production of LH by pituitary cells". Anim. Reprod. Sci., 54(3):203-10, 1999.

Potocnjak, P. \& Bustos, E. Espermatogénesis y duración del ciclo del epitelio seminífero en Octodon degus (Molina). Medio Ambiente, 3:100-11, 1977.

Rodríguez, A.; Rojas, M.; Bustos-Obregón, E.; Urquieta, B. \& Regadera, J. "Distribution of keratins, vimentin, and actin in the testis of two South American Camelids: Vicuna (Vicugna vicugna) and Llama (Lama glama). An Immunohistochemical study". Anal Rec., 254:330-5, 1999.

Thumann, A. \& Bustos, E. An in vitro system for the study of rat spermatogonial proliferative control. Andrologie, 1:22-5, 1978.

Valenzuela-Estrada, M.; Parra, R.; Velasco-Martin, J. P.; Nuñez , H.; Regadera, J. \& Bustos-Obregón, E. Efecto de la maca peruana (Lepidium meyenii) y de la melatonina sobre el desarrollo testicular del ratón expuesto a hipoxia hipobárica continua. Int. J. Morphol., 32(1):70-8, 2014.

Vargas, Álvaro.; Bustos-Obregón, E \& Hartley, R. Effects of hypoxia on epididymal sperm parameters and protective role of ibuprofen and melatonin. Biol. Res., 44(2):161-7, 2011.

Vigil, P. and Bustos-Obregón, E. Alkylating agents and mouse spermatogenesis : Effects of a single dose of cyclophosphamide. Andrología, 17(3):276-82, 1985.
Dirección para Correspondencia:

Dra. Mariana Rojas R.

Laboratorio de Embriología Comparada

Programa de Anatomía y Biología del Desarrollo

Facultad de Medicina, ICBM

Universidad de Chile

Santiago

CHILE

Email: dramrojas@hotmail.com

Recibido: 10-11-2014

Aceptado:11-11-2014 